\title{
Patterns of Psychiatric Morbidity Before and After a War in Lebanon at Twelve Months Following Cessation of Hostilities
}

\author{
Laila F. Farhood* \\ School of Nursing, Clinical Associate, Psychiatry Department, American University of Beirut, Faculty of Medicine, Beirut, \\ Lebanon
}

\begin{abstract}
Objective: This study is a reassessment of the prevalence and predictors of psychiatric disorders in a general population from South Lebanon conducted one year after the July war in 2007, and was thereafter compared to an assessment conducted one year pre-war in 2005 on the same population. This study aims to (1) assess for PTSD, depression and general health in South Lebanon 1 year after the month-long July war, and (2) to report on the results and compare them to pre-war findings in the same population.

Method: This study assessed PTSD, depression, and general health (GHQ) using the Beck Depression Inventory, Harvard Trauma Questionnaire and General Health Questionnaire. The sample consisted of 681 citizens from six villages in South Lebanon using a cross sectional design through random sampling. This sample was compared to another sample of 632 Lebanese citizens interviewed in 2005 before the outbreak of the July war.

Results: Findings revealed a drop in PTSD symptoms in the 2007 sample at a rate of $17.9 \%$ from $24.1 \%$ in 2005 . There was no significant change in depression except in the 60 and above age group. A drop in GHQ-28 scores in 2007 was also observed (4.2 in 2007 from 6.7 in 2005, p value $=<0.001$ )

Conclusion: This reassessment is further evidence that prevalence of mental disorders is difficult to capture in war-torn areas. Social contexts may play a more important role in mental health outcomes of trauma events experienced in developing countries whose civilians suffer continuous armed conflict.
\end{abstract}

Keywords: Depression, general health, pre and post war, psychiatric disorder, PTSD, South Lebanon.

\section{INTRODUCTION}

Advances in trauma research began in military personnel and have since then sparked a vast amount of insight into the human response to traumatic experiences [1,2] mainly introducing the concept of Posttraumatic Stress Disorder (PTSD). Recently, more attention has been directed towards the effects of mass community trauma following natural or man-made disasters [3-6]. Although community devastations have been studied, the most long-lasting and devastating of community trauma is that caused by war, armed conflict, or mass violence [7]. Studies on the psychological effects of war have been conducted on civilian populations, however, little is still known concerning the effects of continuous armed conflict on civilians residing in volatile areas $[5,8$ 10]. Refugee studies are abundant and have shed light on the experience of civilians during and after conflict in terms of prevalence rates of psychiatric morbidity, risk factors and adjustment [11-14]. Such studies share several findings, specifically that the exposure to a traumatic event increases the likelihood of mental health disorders. Additionally, studies have shown higher prevalence rates in conflict-ridden

\footnotetext{
*Address correspondence to this author at the School of Nursing, American University of Beirut, Faculty of Medicine, P.O. Box 11-0236, Riad El-Solh / Beirut 1107 2020, Lebanon; Tel: -961-1-350-000, Ext. 5975;

Fax: -961-1-744-476; E-mail: 1f00@aub.edu.lb
}

areas compared to Western countries where little conflict takes place. For example, according to the National Comorbidity Survey, prevalence rates in the US were found to be $10.4 \%$ in women and $5.0 \%$ in men in the general population [15]. Additionally, de Jong et al. [16] assessed prevalence rates in conflict-ridden countries and found varying rates from $15.8 \%$ in Ethiopia, $37.4 \%$ in Algeria, $17.8 \%$ in Gaza and $28.4 \%$ in Cambodia. The literature addresses several possible risk factors for mental disorders resulting from trauma exposure. For example, Adams \& Boscarino [17] found one year after the World Trade Center Attacks $(n=2,368)$ that proximity to the events, or rather, the more exposed the individual is to the events, the more likely they are to experience more psychological problems. However, the risk factor most associated with the psychological effects of trauma is previous exposure $[9,14$, $16]$.

Communal recovery and processing of war events may have implications on contemporary theories and raise questions about the validity of Western concepts in understanding trauma in culturally diverse areas and in providing appropriate treatment for psychiatric problems in areas afflicted by war [18-20]. In a study looking at the lifetime prevalence of mental disorders in the decades of the Lebanon wars, it was found that nearly half of the Lebanese population $(47 \%)$ was exposed to one to two trauma events 
with $25.58 \%$ meeting DSM-IV criteria for at least one disorder [21].

The current study seeks to compare psychiatric morbidity and general health 1 year before and after a war in the South Lebanon, a highly volatile area in which communities are continuously exposed to trauma and are therefore at risk of mental health related problems. The uniqueness of this study is that it assessed the same population of specific villages in South Lebanon twice over two different time periods before and after conflict. This study may thus shed insight into community experiences during times of mass violence, instability and other war related events.

\section{BACKGROUND}

For over 3 decades, the Lebanese population has experienced periods of armed conflict and foreign occupation. In 1975, a civil war embroiled the country into mass violence and destruction lasting for more than 15 years [22]. South Lebanon was occupied by Israel for over 20 years, during which sporadic conflict erupted between occupying forces and local militant groups, resulting in hundreds of civilian deaths and casualties on both sides of the border [23]. According to the UN Security Council Report [24], sporadic conflict on both fronts continued even after the withdrawal of occupying forces in the year 2000. In 2005, five years after withdrawal from South Lebanon, a study by Farhood et al. was conducted on six Southern Lebanese villages. The aim was to assess prevalence and predictors of PTSD, depression and general health $[9,25]$.

On July 12, 2006 another armed conflict broke out on the Lebanese-Israeli border. According to the World Health Organization (WHO) 2006 report, the conflict affected the entire Lebanese population with most of the devastation and displacement occurring in the south [26]. The 2006 war lasted 33 days resulting in more than 1,187 Lebanese civilian deaths and 4,092 injuries. The cost of the damages to Lebanese infrastructure and buildings was estimated at $\$ 3.5$ billion USD [22]. The author, again, conducted another study on the same villages using random sampling. The aim was to reassess, and contrast findings as compared to the previous study.

In areas afflicted by war and conflict, individuals and their communities are subjected to devastating consequences that may leave severe psychological scars. As of 2008, there were an estimated 26 million internally displaced people or IDPs worldwide due to conflict [27]. Little is known of the psychological consequences of continuous wars in civilian populations $[5,16]$. Studies looking at postwar environments have shown changes in prevalence rates of mental disorders across time [12, 28]. Additionally, studies have shown an association between increases in PTSD symptoms and multiple trauma exposure following conflict in civilian populations [8, 17, 29, 30]. For example, Abu-Saba [31] conducted a study 4 years after the civil war in Lebanon on an undergraduate university sample (avg. age $=20 ; \mathrm{n}=$ 1268) and found that the more war events experienced increased the likelihood of scoring high on anxiety, depression and PTSD scales.
The civilian populations in South Lebanon have experienced continuous armed conflict, yet few studies have conducted mental health assessments of the affected communities. Farhood, Dimassi \& Lehtinen [9] found that $97.7 \%$ of the studied sample had experienced, witnessed, or heard of war-related traumatic events in two towns Southern Lebanon with $29.3 \%$ prevalence rates of PTSD and a mean total GHQ score of 10.46 . The authors concluded that mental health was adversely affected by exposure to war-related events and other factors including a 20-year occupation. In a similar study conducted on a Lebanese population $(n=2857$ adults) showing the association between war trauma and psychiatric morbidity, Karam et al. [21] found a lifetime prevalence of $25.8 \%$ for mental disorders noting that exposure to war events increases the onset of psychiatric symptoms.

This study re-assesses the mental health of a population in the south of Lebanon one year following the 2006 war and compares the results to a previous study conducted in 2005 on the same population. The 2005 survey findings revealed prevalence rates averaging $24.1 \%$ for PTSD and $14.1 \%$ for depression [9]. Although under unfortunate circumstances, there existed an opportunity not to be missed in conducting both studies: one in 2005, to assess psychiatric morbidity after chronic exposure to war while under occupation, and another in 2006 following the occupation of Southern Lebanon for 33 days. According to Farhood, Dimassi, \& Strauss (2013), a mental health assessment performed on inhabitants of South Lebanon post the 2006 war revealed that exposure to war and war-related events are highly associated with psychiatric problems such as PTSD, depression, and general health status one year after exposure to violent conflict [33].

Understanding how continuous conflict and distress affects civilians and communities over time continues to be of great importance. A limited number of studies are similar in methodology to the one conducted. Cardozo et al. conducted a study on an Albanian Kosovar population, exposed to massive violence and instability one year postwar. The course of PTSD was examined in a group of returning refugees and IDPs and compared results to a mental health survey administered six weeks after the start of the conflict. The authors found an increase in PTSD prevalence rates to $25 \%$ from $17.1 \%$ showing a relationship between rates of mental health problems and trauma exposure [28].

According to the literature, there is a definite relationship between continuous exposure to war and increases in rates of psychiatric symptoms. However, rates are not consistent across countries $[16,26,32]$. Further assessment is needed in communities experiencing ongoing conflict in order to better understand the course of the effects of war on civilians [28]. To date, no other study has been conducted assessing PTSD, depression and general health outcomes following war exposure in a civilian adult population both before and after recurring exposure to an armed conflict. 


\section{AIM OF STUDY}

This study aims to (1) assess for PTSD, depression and general health in South Lebanon 1 year after a one- month war, and (2) to report on the results and compare them to pre-war findings in the same population.

\section{METHOD}

\section{Study Design}

This study aims to compare results from one year pre war (2005) to one year post war (2007). As such, the design and procedure used in the one year pre-war study was replicated in 2007 assessing the same six villages from the 2005 study. The areas in the survey were characterized by geographical diversity. The sample was diverse in age, gender, religion, and educational background. Details of the procedure and sample size calculation can be found in previous research conducted by Farhood, Dimassi, and Lehtinen [9]. The sample size was based at 20\% (CL-15$25 \%)$ expected prevalence of mental health outcome $(15$, 39). The calculated sample size required was 125 per village. This was found to yield a power of $80 \%$ allowing for a $5 \%$ risk of Type I error. The analysis for sample size was calculated using the PASS software which is part of the NCSS statistical package. The sample size was increased for villages $\mathrm{H}$ and $\mathrm{KH}$ to 150 . Due to the close similarities in villages $\mathrm{B}$ and $\mathrm{D}$, the samples were combined reducing the total sample size to 75 .

\section{Sampling Procedure}

A multi-stage cluster sampling was used with the village being the first level, rural blocks as second level, and finally individual households.

Permanent residents, age 20 or older, who lived during the occupation of Southern Lebanon for two years or more were eligible. One member per household was selected. Those who were physically or mentally unable to be interviewed were not selected for participation. A quota was introduced to increase sample representation with regards to age and gender. The rationale for using quotas at the household level was to reflect the population distribution in the selected areas. The Quotas were established using the United Nations report [22].

The participants were asked for oral informed consent and remained anonymous throughout the study. Secondary to the highly sensitive political situation in the area throughout the occupation, additional special attention was given to maintaining anonymity throughout the study. As such, written consent was thus decided against in order to protect the participants' privacy as well as take into consideration the varying educational levels, opting for oral consent as the best alternative. Face-to-face consent and interview were therefore the best chosen method specifically since anonymity not only posed a security challenge but also a cultural one. Moreover, interviews were chosen over selfreport measures since it was expected that some respondents would not have a sufficient level of education to neither give written consent nor answer self-report questionnaires, and would thus likely be most comfortable with oral consent and face-to-face interview over written consent and response. The interviews were conducted by interviewers who were prepared for the interviewing process by undergoing sessions on the subject of the study, interviewing technique, and the specific questionnaire used, and participants were interviewed in-home and face-to-face using pen and paper. There was no financial compensation for participation. The ethical approval for the study was granted by the American University of Beirut Institutional Review Board.

\section{Instruments}

The same measures were used in both the 2005 [9] and the 2007 survey to assess mental health: the Harvard Trauma Questionnaire (HTQ) [12]; Beck Depression Inventory (BDI) [34]; General Health Questionnaire-28 (GHQ-28) [35].

\section{Exposure and PTSD}

The Arabic version of the Harvard Trauma Questionnaire (HTQ) assesses exposure to traumatic events and current PTSD symptoms with 2.5 as cut-off point for current PTSD. The HTQ psychometric properties are as follows: inter-rater reliability $r=0.93$ for the traumatic events, $r=0.98$ for symptoms and on-week test-retest reliability $r=0.89$, $\mathrm{p}<0.0001$ for traumatic events, and $\mathrm{r}=0.92, \mathrm{p}<0.0001$ for trauma symptoms [30]. Cronbach's alpha was calculated to be 0.87 for the symptom part of the Arabic version.

\section{Beck Depression Inventory (BDI)}

The BDI is a 21 item rating inventory measuring characteristics, attitudes, and symptoms of depression [34]. Cutoff point of 9 indicates mild depression and above 19 moderate to severe depression. The internal consistency ranges from 0.73 to 0.92 with a mean of 0.86 [36]. It has a split-half reliability co-efficient of 0.93 , as well as a high internal consistency with alpha coefficients of 0.86 and 0.81 for psychiatric and non-psychiatric populations respectively [36]. BDI has been used extensively on the Lebanese population $[37,38]$.

\section{General Psychiatric Morbidity}

General psychiatric morbidity was measured using the General Health Questionnaire-28 (GHQ-28) consisting of four subscales: somatic symptoms, anxiety and insomnia, social dysfunction and severe depression [35]. Multiple international assessments have demonstrated structural consistency in different settings and languages [39]. The validity and reliability of the Arabic GHQ-28 was addressed in previous research studies. The sensitivity, specificity and internal consistency were found to be $0.87,0.49$, and 0.93 respectively [40]. It has been widely used on Arab and specifically Lebanese populations $[9,37,41]$. The Cronbach's alpha for this study was 0.87 . Items from each subscale were scored and added compiling two scores: subscale and total score.

\section{Data Analysis}

Data were coded and compiled into SPSS 21. For the purpose of the study, data analysis was limited to results from the six villages include in both 2005 and 2007 samples. 
The 2005 and 2007 samples were compared on sociodemographic characteristics to determine if there were any underlining differences that might affect the results. Then a comparison of PTSD and Depression rates, as well as GHQ scores was done on the two samples, while correcting for statistically significant socio-demographic variables. To examine the possible effect of age and gender, a stratified comparison by these two variables was conducted. Finally, war events experienced in 2005 and 2007 were examined to determine which events were experienced at a higher or lower rate. Differences in the samples were tested using the Pearson Chi-square or the student t- test according to the type of data. All analyses were done at the 0.05 level.

\section{RESULTS}

The two samples (2005 and 2007) were similar in their general characteristics except for education. The sampling procedures followed in both studies were done in a way that the age and gender distribution in the Lebanese population reflected the quotas set by the United Nations report [22]. As expected, both samples had similar distribution of gender and age groups ( $\mathrm{p}$ - values $=0.458$ and 0.399 respectively), with equal representation of the genders and a majority being between 18 and 30 years of age. About $63 \%$ of the 2005 sample and $59 \%$ of the 2007 sample were married ( $\mathrm{p}$-value $=$ 0.283 ), half were employed ( $46.7 \%$ and $48.3 \%$ respectively), and $11.6 \%$ and $8.8 \%$ respectively unemployed ( $\mathrm{p}$-value $=$ 0.096). As for education, there were more participants with higher education in the 2007 sample than in the 2005 sample as reflected by the $45.5 \%$ with secondary or more education (vs 38.9\%) and $11.7 \%$ with below primary education ( $v s$ $18.7 \%)(p$-value $=0.001)($ Table 1$)$.

The proportion of respondents with PTSD was lower in 2007 than in the 2005 sample. In $2007,17.9 \%$ of the sample scored higher than the cut-off point on the HTQ, as compared to $24.1 \%$ in 2005 ( $\mathrm{p}$-value $=0.002$ ). There was no statistical difference in the proportion of participants scoring higher than the cut-off point on the BDI between the 2005 and 2007 samples $(14.1 \%$ and $13.4 \%$ respectively, $\mathrm{p}$-value $=$ 0.752). The scores on the GHQ-28 were lower in the 2007 sample then in the 2005 sample for all subscales as well as the total score (4.2 in 2007 from 6.7 in 2005, p value$<0.001)$. There were similar drops in somatization and anxiety subscales scores from 1.8 to 1.2 (both $\mathrm{p}$-values = $<0.001)$. A more pronounced drop was observed in the social dysfunction scores as the average in 2005 was 2.5 and dropped to 1.5 in 2007 (p-value < 0.001). Severe depression subscale had the lowest score in both samples, and as such the drop in the score was observed to be the least amongst all other subscales from 0.62 to 0.34 (p-value $<0.001$ ) (Table 2). Table 3 shows the stratified results by age and gender. Change in PTSD from 2005 to 2007 was not statistically significant for men $(15.2 \%$ to $10.0 \%$ respectively, $\mathrm{p}$-value $=$ $0.053)$. Contrary to all other age groups, the 60 and above age group displayed an increase in depression $(10.7 \%$ to $27.5 \%$; p-value $=0.006$ ) and no statistical change in any of the GHQ sub-scores.
Table 1. Comparison of frequency and percentage distribution of sample characteristics.

\begin{tabular}{|c|c|c|c|}
\hline & $\begin{array}{c}2005 \\
\text { N }(\%)\end{array}$ & $\begin{array}{c}2007 \\
\text { N }(\%)\end{array}$ & P-Value \\
\hline Sample Size & 632 & 681 & \\
\hline \multicolumn{4}{|l|}{ Age } \\
\hline $20-29$ & $181(28.7 \%)$ & $212(31.1 \%)$ & \multirow{5}{*}{0.399} \\
\hline $30-39$ & $152(24.1 \%)$ & $179(26.3 \%)$ & \\
\hline $40-49$ & $115(18.3 \%)$ & $112(16.4 \%)$ & \\
\hline $50-59$ & $67(10.6 \%$ & $76(11.2 \%)$ & \\
\hline $60+$ & $115(18.3 \%)$ & $102(15.0 \%)$ & \\
\hline \multicolumn{4}{|l|}{ Gender } \\
\hline Male & $309(48.9 \%)$ & $319(46.8 \%)$ & \multirow{2}{*}{0.458} \\
\hline Female & $323(51.1 \%)$ & $362(53.2 \%)$ & \\
\hline \multicolumn{4}{|c|}{ Marital Status } \\
\hline Single & $199(31.5 \%)$ & $243(35.7 \%)$ & \multirow{3}{*}{0.283} \\
\hline Married & $396(62.8 \%)$ & $401(58.9 \%)$ & \\
\hline Other & $36(5.7 \%)$ & $37(5.4 \%)$ & \\
\hline \multicolumn{4}{|l|}{ Education } \\
\hline Level 1 & $118(18.7 \%)$ & $80(11.7 \%)$ & \multirow{3}{*}{0.001} \\
\hline Level 2 & $268(42.4 \%)$ & $292(42.9 \%)$ & \\
\hline Level 3 & $246(38.9 \%)$ & $309(45.4 \%)$ & \\
\hline \multicolumn{4}{|l|}{ Employment } \\
\hline Employed & $295(46.7 \%)$ & $329(48.3 \%)$ & \multirow{4}{*}{0.096} \\
\hline Unemployed & $73(11.6 \%)$ & $60(8.8 \%)$ & \\
\hline Housewife & $195(30.9 \%)$ & $194(28.5 \%)$ & \\
\hline Other & $69(10.9 \%)$ & 98 (14.4\%) & \\
\hline
\end{tabular}

Level 1: below primary education.

Level 2: not completed secondary education.

Level 3: secondary education or more completed.

When asked about experiencing any of the traumatic events listed in the HTQ, $86.4 \%$ of the participants reported at least one of the events in 2005 . This proportion was higher in 2007 reaching $94.4 \%$ of the total sample ( $\mathrm{p}$-value = $<0.001)$. A closer look at the individual traumatic events reveals a certain trend, whereby some of the events were experienced at a higher proportion in 2005 than in 2007. Table 4 lists the events most experienced in 2007 versus 2005.

\section{DISCUSSION}

The objective of this study was to re-assess populations in the six villages studied South of Lebanon for the prevalence of PTSD, depression and general health one year after a war that took place in July 2006 and compare the results to a study conducted on these villages in 2005 [25]. To date, no other study has assessed psychiatric morbidity 
Table 2. Comparison of sample characteristics by PTSD, Depression and GHQ.

\begin{tabular}{|l|c|c|c|}
\hline & $\begin{array}{c}\mathbf{2 0 0 5} \\
\mathbf{N = 6 3 2}\end{array}$ & $\begin{array}{c}\mathbf{2 0 0 7} \\
\mathbf{N = 6 8 1}\end{array}$ & P-Value \\
\hline \hline PTSD & $150(24.1 \%)$ & $122(17.9 \%)$ & 0.002 \\
\hline Present & \multicolumn{5}{|l|}{} \\
\hline Depression & \multicolumn{4}{|l|}{} \\
\hline Moderate to severe & $53(14.1 \%)$ & $91(13.4 \%)$ & 0.752 \\
\hline GHQ-28 Score: Mean (SD) & $4.2(4.8)$ & $<0.001$ \\
\hline Total & $1.8(1.9)$ & $1.2(1.7)$ & $<0.001$ \\
\hline Somatization & $1.8(2.1)$ & $1.2(1.8)$ & $<0.001$ \\
\hline Anxiety & $2.5(2.1)$ & $1.5(1.7)$ & $<0.001$ \\
\hline Social Dysfunction & $62(1.25)$ & $.34(.87)$ & $<0.001$ \\
\hline Severe Depression &
\end{tabular}

PTSD: assessed using the Harvard Trauma Questionnaire (HTQ).

GHQ-28: The general Health Questionnaire 28 items version.

Depression: assessed using the Beck Depression Scale.

Beck Depression Scale: only used in villages $\mathrm{H}, \mathrm{KH}$ and BD.

All p-values are corrected for education. and general health pre and post conflict on the same population. Furthermore, this study provides a unique insight into multiple trauma exposure in culturally diverse areas.

Though there was a devastating war that occurred in 2006 in South Lebanon, the mental health indicators assessed in this study did not pick up any increase that would be otherwise expected. There was no change in depression in both samples, an indicator of stable factor due to prolonged traumatic events.

When age and gender was examined, a statistical significance was observed. For example, in age groups 60 and above there was an increase in depression from the BDI, which could be indicative of a group that was exposed to the most war trauma over time [42]. Additionally, no change was seen in the GHQ sub-scores compared to all other gender and age groups in which scores decreased (Table 3). Further, there was no significant change in male PTSD scores from 2005 and 2007.

In terms of other psychiatric symptoms and general health, with respect to the entire sample, we expected to find an increase in scores but saw a decrease. Findings in 2005 show prevalence rates of PTSD to be $24.7 \%$. However, in 2007 rates of PTSD decreased to $17.9 \%$ (Table 2). Similar

Table 3. Mental health outcomes pre (2005) and post (2007) war by gender and age.

\begin{tabular}{|c|c|c|c|c|c|c|c|}
\hline & \multicolumn{2}{|c|}{ Gender } & \multicolumn{5}{|c|}{ Age Groups } \\
\hline & Men & Women & 20-29 & 30-39 & $40-49$ & $50-59$ & $60+$ \\
\hline 2005 PTSD & $46(15.2 \%)$ & $104(32.6 \%)$ & $31(17.7 \%)$ & $33(22.1 \%)$ & $33(28.7 \%)$ & $25(38.8 \%)$ & $27(23.7 \%)$ \\
\hline 2007 PTSD & $32(10.0 \%)$ & $90(24.9 \%)$ & $21(9.9 \%)$ & $35(20.1 \%)$ & $28(25.0 \%)$ & $11(14.5 \%)$ & $25(25.5 \%)$ \\
\hline p-value & 0.053 & 0.026 & 0.025 & 0.652 & 0.530 & 0.001 & 0.758 \\
\hline 2005 Depression & $23(12.1 \%)$ & $30(16.0 \%)$ & $11(10.7 \%)$ & $12(13.2 \%)$ & $12(17.9 \%)$ & $10(24.4 \%)$ & $8(10.7 \%)$ \\
\hline 2007 Depression & $35(11.0 \%)$ & $56(15.5 \%)$ & $17(8.0 \%)$ & $21(11.7 \%)$ & $16(14.3 \%)$ & $9(11.8 \%)$ & $28(27.5 \%)$ \\
\hline p-value & 0.697 & 0.861 & 0.436 & 0.730 & 0.518 & 0.079 & 0.006 \\
\hline 2005 GHQ total & $6.1 \pm 5.6$ & $7.3 \pm 5.8$ & $6.0 \pm 5.0$ & $6.2 \pm 5.6$ & $7.3 \pm 5.8$ & $9.0 \pm 7.2$ & $6.6 \pm 5.7$ \\
\hline 2007 GHQ total & $3.7 \pm 4.6$ & $4.7 \pm 5.0$ & $3.3 \pm 4.2$ & $3.8 \pm 4.3$ & $5.2 \pm 5.7$ & $3.7 \pm 3.5$ & $6.1 \pm 6.1$ \\
\hline p-value & $<0.001$ & $<0.001$ & $<0.001$ & $<0.001$ & $<0.001$ & $<0.001$ & 0.593 \\
\hline 2005 Somatization & $1.5 \pm 1.7$ & $2.1 \pm 2.1$ & $1.2 \pm 1.5$ & $1.5 \pm 1.8$ & $2.1 \pm 2.0$ & $2.7 \pm 2.4$ & $2.2 \pm 2.1$ \\
\hline 2007 Somatization & $0.9 \pm 1.4$ & $1.5 \pm 1.9$ & $0.7 \pm 1.3$ & $1.0 \pm 1.6$ & $1.7 \pm 1.9$ & $1.2 \pm 1.5$ & $1.9 \pm 2.1$ \\
\hline p-value & $<0.001$ & $<0.001$ & 0.001 & 0.013 & 0.103 & $<0.001$ & 0.392 \\
\hline 2005 Anxiety & $1.5 \pm 2.0$ & $2.0 \pm 2.2$ & $1.5 \pm 1.9$ & $1.7 \pm 2.2$ & $2.0 \pm 2.1$ & $2.5 \pm 2.7$ & $1.5 \pm 1.9$ \\
\hline 2007 Anxiety & $1.0 \pm 1.7$ & $1.3 \pm 1.9$ & $1.0 \pm 1.7$ & $1.2 \pm 1.8$ & $1.4 \pm 2.0$ & $0.8 \pm 1.1$ & $1.5 \pm 2.2$ \\
\hline p-value & 0.001 & $<0.001$ & 0.007 & 0.009 & 0.040 & $<0.001$ & 0.997 \\
\hline 2005 Social Dysfunction & $2.6 \pm 2.2$ & $2.5 \pm 2.1$ & $2.6 \pm 2.1$ & $2.4 \pm 2.1$ & $2.7 \pm 2.2$ & $2.9 \pm 2.3$ & $2.3 \pm 2.1$ \\
\hline 2007 Social Dysfunction & $1.4 \pm 1.7$ & $1.5 \pm 1.7$ & $1.3 \pm 1.5$ & $1.3 \pm 1.4$ & $1.7 \pm 1.8$ & $1.6 \pm 1.8$ & $2.1 \pm 2.0$ \\
\hline p-value & $<0.001$ & $<0.001$ & $<0.001$ & $<0.001$ & $<0.001$ & $<0.001$ & 0.563 \\
\hline 2005 Severe Depression & $0.6 \pm 1.1$ & $0.7 \pm 1.4$ & $0.7 \pm 1.3$ & $0.6 \pm 1.1$ & $0.5 \pm 1.2$ & $0.9 \pm 1.4$ & $0.6 \pm 1.3$ \\
\hline 2007 Severe Depression & $0.3 \pm 0.9$ & $0.4 \pm 0.8$ & $0.3 \pm 0.8$ & $0.3 \pm 0.7$ & $0.4 \pm 1.1$ & $0.2 \pm 0.5$ & $0.6 \pm 1.1$ \\
\hline p-value & 0.005 & $<0.001$ & 0.001 & 0.013 & 0.457 & $<0.001$ & 0.896 \\
\hline
\end{tabular}


Table 4. Comparison of the 2005 and 2007 HTQ responses of experienced war events.

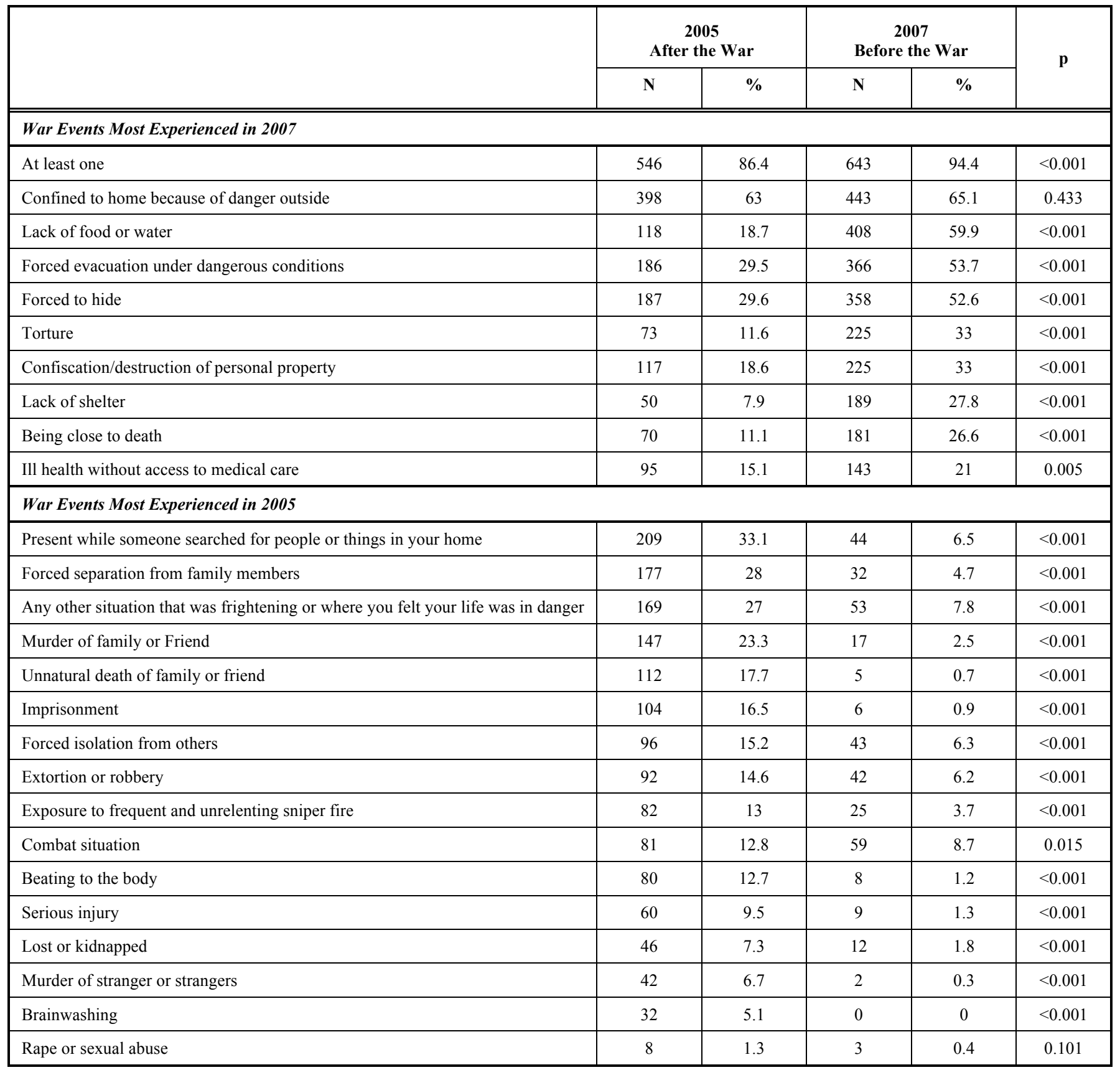

findings were found amongst a student population with authors suggesting that distress decreases with multiple traumatic events, or rather the ability to cope and social support may lessen the impact of trauma events [43]. Norris et al. [5] found supporting evidence across studies that perceived coping or belief in one's ability to cope with a disaster protects against negative mental and physical health outcomes than measured in actual coping. Additionally, PTSD symptoms may decrease after cessation of certain types of conflicts (e.g. long occupation vs brief armed conflict). According to de Jong [16], an occupation of forces may be more traumatic for the civilians due to the duration of trauma exposure. This could explain why the 2005 study, in which civilians were assessed following a 20 year occupation, reported higher symptoms than in 2007, reflecting the role of cumulative trauma. Another important factor was the role of social support and aid practiced by political parties in the rebuilding process. These factors need reassessment in order to check for the long term consequences of exposure to said traumas.

In a similar study conducted by Cardozo et al. [28] following mass violence, displacement and war-conflict in Kosovo, the authors found an increase in PTSD prevalence rates of $25 \%$ in their 2000 survey compared to $17.1 \%$ in 1999 as measured by the HTQ six weeks following a conflict. However, with regards to GHQ scores, they had similar findings to the current study. The present study had an improvement in GHQ total scores from 6.7 to $4.2,2005$ and 2007 respectively where Cardozo et al. [28] observed 
improved scores of 11.1 to 8.2 . Findings in the current study revealed decreases in sub-scores for the same subscales with the inclusion of severe depression. It is important to note that approximately 900,000 people, a quarter of the population of Lebanon, were displaced during the 2006 war [27]. In this sample, 431 out of $681(63.3 \%)$ were displaced. However, no significant differences were found in reporting of traumatic events between those who left and those who stayed (data not shown). Similar results were found in Kosovo [28].

Responses from the HTQ also revealed an increase in trauma exposure however there was a significant decrease in number of types of events experienced. There were nine events experienced by the 2007 participants at a higher rate than the 2005 sample. An example is lack of food and water, where $60 \%$ of participants reported experiencing this traumatic experience in 2007 compared to only $18.7 \%$ in 2005 (p-value $=<0.001)$. According to the 2006 UNIFIL report [22], the South of Lebanon saw the destruction of an estimated 15,000 homes and damage to infrastructure such as bridges, roads, factories, water and sewage plants, dams and electrical plants, which would inhibit the flow of vital resources to this population. The remaining 16 events listed by the HTQ were more experienced in the 2005 sample than in 2007. An example of these events is "present while someone searched for people or things in your home". This was reported by one third of the participants in 2005 as compared to only $6.5 \%$ in 2007 sample (Table 4).

These differences in type and frequency of trauma reporting on the HTQ can be explained in two ways. First, the trauma experiences that increased in the 2007 assessment can be seen as characteristic of the 2006 war, such as bombardments, shortage of food and displacement. Whereas in the 2005 sample, the participants had been under military occupation and mostly reported events involving constant instability, forced searches of one's home, and challenges to daily activities over a long period of time. A closer examination of the reported trauma events may characterize the type of conflict (occupation $v s$ brief armed conflict). In a study on conflict areas, de Jong [16] suggested that trauma varies with types of conflict (i.e. duration and intensity) with the most enduring effects from an occupation in which the trauma exposure lasts longer. Second, the number of events experienced may indicate a cumulative effect increasing the likelihood of PTSD. According to Eytan [8], a strong cumulative effect of the number and different types of trauma events were found to be experienced due to the likelihood of having PTSD. In the 2005 sample, 16 events were experienced compared to 9 events in 2007 (Table 4). This cumulative effect of different types of trauma could also explain the differences in PTSD scores (Table 2). Additionally, Cardozo [28] looked at traumatic events experienced and found that prevalence of trauma events decreased from 1998 to 2000 . The authors discuss this decrease as being a failure to recall past events and assert that certain types of trauma may be more socially acceptable to report one year later. Given the historically sensitive political atmosphere of the south secondary to conflict, reporting of certain trauma events may have been affected, explaining the differences in types of trauma reported. The majority of the population supports the political atmosphere that defended the South against the invasion. This war was regarded as a victory despite the destruction endured, especially with the victorious, resilient atmosphere that consequently developed after the 2006 war [44], thus suffering may have been instead overlooked, taken for granted the post-war situation, and was therefore not readily reported as psychological distress.

PTSD as the psychopathological response to traumatic stress has been shown to be a universal and cross-culturally valid concept [12]. However, according to McFarlane [45], a decrease in PTSD following a traumatic experience challenges the concept of the psychiatric disorder. There has been a wide-standing argument against the validity of the concept of PTSD in non-Western countries, specifically those stricken by war $[9,18,19,32]$.

Bracken et al. [18] \& Kienzler [19] assert that PTSD, as a western concept, may not be applicable to culturally diverse areas. Bracken et al. [18] theorizes that the individualized model of suffering which focuses on psychological distress characterizes the western concept of PTSD, limiting nonwestern populations in that it does not take into account culture, religion and politics, all of which significantly impact traumatized communities.

With regards to populations in the south of Lebanon who have endured decades of suffering, it is important to identify sociocultural factors that will enhance coping and allow for appropriate treatment for mental health problems. In terms of coping with mass violence, McFarlane et al. [45] asserts long-term adaptability as being determined by tolerance to the suffering suggesting that the more an individual is exposed to the trauma the more coping or avoidance develops. Further, vulnerability vs resilience explains why PTSD does not occur in everyone. Vulnerability factors (low education, female with child, presence or history of psychiatric illness) $[5,8,9]$ contribute to an increase in the psychological impact of trauma, whereas resiliency, defined by Norris et al. [46] as "adaptability" or rather an individual's ability to overcome the response to stress, has been shown to protect against psychological symptoms that can result from traumatic experiences. Additionally, higher education level has been associated with lower symptom levels. In this current study, the 2007 sample had higher education level than the 2005 sample indicating a possible protective factor against negative symptoms of trauma $[37,43]$. Although this discrepancy in educational levels between the two samples exists, leading to varying severity of symptoms as well as possible change in behavior, it is interesting to note that in the 2007 sample this may have both protected against posttraumatic psychiatric symptoms as well as contributed to the increased adaptability and recoverability towards the overall ability to cope with change and overcome the post-war conditions existing in South Lebanon.

With regards to this comparison study in a war conflict area, resources play a key role and may aid as a determinant of social functioning. Indeed, in a study conducted on a Lebanese population by Farhood [29] found that a loss in 
resources, such as home, finances, and social support, could aid as predictors of the psychological effects of trauma in conflict societies. According to Freedy et al. [47], this may indicate psychological impact of exposure since loss of resources is associated with increase in distress. The reverse is true that if resources are perceived as stable, then individuals are protected from the effects of trauma [47]. Following the brief war in 2006, the southern Lebanese population may not have perceived a great loss in resources, secondary to the victorious atmosphere and unified resilience in rebuilding with triumphant financial and social support. After the 2006 war, the civilians of South Lebanon felt a more collective identity, with an increased sense of unity, resilience, and coping with change especially after recurring conflict, promoting the integration of their newfound collective victorious strengths into relief efforts [44]. Thus, despite the sharp drop in resources directly after the traumatic 2006 war, the perception of the Southern Lebanese population in these six villages was one of higher community pride and togetherness in better overcoming the occupational conflict [44].

In conclusion, this study provides further evidence that predicting psychiatric morbidity in non-western countries following multiple war related events is difficult and raises important concerns in research for sociocultural sensitive assessments and treatment of psychological disorders in civilian populations who have suffered war, political conflict and mass violence.

Similar conclusions have been made in numerous warconflict and refugee studies [10, 11, 14, 20, 48, 49]. In this current study, a higher rate of traumas were experienced at in 2007 indicating vulnerability in participants to the effects of war, thus calling for a need to intervene in those individuals with present psychiatric symptoms. Furthermore, this study supports the need to understand cultural, religious and social belief systems as a way in which people cope with trauma and examine their protective role against psychiatric disorders. Within the Southern Lebanese culture, spirituality and religion is turned to as a coping mechanism and search for relief, and is in turn a protective, socially approved method of dealing with the taboo of having a psychiatric disorder. Such comparative research could help mitigate short and long term impact that war and mass violence inflicts on civilians. Individuals could have been suffering but underreport symptoms based on what is socially acceptable following a war such as the one in July 2006 in which individuals may have identified with the outcome of the war in a political and social context. Additionally, the internal and international recovery effort was immediate despite limitations due to bombardments, but civilians were able to receive aid [22]. Early aid responses were seen in Kosovo as well and the authors noted aid efforts as a protective factor and predictor of early recovery [28].

The main limitations of the study include 1) recall bias, or, "reporting bias" in which there is a systematic error in recalling of past events or experiences and 2) lack of measurements of the same person over time in a longitudinal study. Another issue is the uniqueness of the study itself, in that studies showing the effects of pre and post war conflict in the same civilian population are rare and thus may not allow comparability of our results with other findings. Additionally, it is important to note that findings cannot be generalized to other than the six villages reported in the study, and therefore may limit representation of these findings to be generalized to all of South Lebanon, but only to these six villages alone. However, the pre- and post- war assessments reported in this studied population are vital findings in assessing such outcomes, potentiating the possibility for future research verifying these aforementioned concepts of possible mental health disorders in the South Lebanon area.

Further analysis is thus needed to identify village and other characteristics which may provide further insight. Authors are currently addressing the effect of village characteristics and psychiatric morbidity and cumulative effects of traumas with regards to PTSD, depression and general health from the 2005 and 2007 data. Findings may not only offer insight into results from this survey but also aid in the development of appropriate interventions which take into account cultural, social and political contexts which exist in such a diverse and conflict prone area as Lebanon and in other war-torn countries.

\section{CONFLICT OF INTEREST}

The author confirms that this article content has no conflict of interest.

\section{ACKNOWLEDGEMENTS}

Many thanks to Nora KAKATI, MSN Student, for her editorial review.

\section{REFERENCES}

[1] Solomon Z, Weisenberg M, Schwarzwald J, Mikulincer M. Posttraumatic stress disorder among frontline soldiers with combat stress reaction: The 1982 Israeli experience. Am J Psychiatry 1987; 144(4): 448-454

[2] Van Putten T, Yager J. Posttraumatic stress disorder: Emerging from the rhetoric. Arch Gen Psychiatry 1984; 41(4): 411-413.

[3] Galea S, Nandi A, Vlahov D. The epidemiology of post-traumatic stress disorder after disasters. Epidemiol Rev 2005; 27: 78-91.

[4] Goenjian AK, Steinberg AM, Najarian LM, Fairbanks LA, Tashjian M, Pynoos RS. Prospective study of posttraumatic stress, anxiety, and depressive reactions after earthquake and political violence. Am J Psychiatry 2000; 157(6): 911-916.

[5] Norris FH, Friedman MJ, Watson PJ. 60,000 disaster victims speak: Part II. Summary and implications of the disaster mental health research. Psychiatry: Interpersonal and Biological Processes 2002; 65(3): 240-260.

[6] Önder E, Tural Ü, Aker T, Kılıç C, Erdoğan S. Prevalence of psychiatric disorders three years after the 1999 earthquake in Turkey: Marmara Earthquake Survey (MES). Soc Psychiatry Psychiatr Epidemiol 2006; 41(11): 868-874.

[7] Norris FH, Friedman MJ, Watson PJ, Byrne CM, Diaz E, Kaniasty K. 60,000 disaster victims speak: Part I. An empirical review of the empirical literature, 1981-2001. Psychiatry: Interpersonal and biological processes 2002; 65(3): 207-239.

[8] Eytan A, Gex-Fabry M, Toscani L, Deroo L, Loutan L, Bovier PA. Determinants of postconflict symptoms in Albanian Kosovars. J Nerv Ment Dis 2004 Oct; 192(10): 664-671.

[9] Farhood L, Dimassi H, Lehtinen T. Exposure to war-related traumatic events, prevalence of PTSD, and general psychiatric morbidity in a civilian population from Southern Lebanon. J Transcult Nurs 2006 Oct; 17(4): 333-340.

[10] Mollica RF, McInnes K, Sarajlić N, Lavelle J, Sarajlić I, Massagli MP. Disability associated with psychiatric comorbidity and health 
status in Bosnian refugees living in Croatia. JAMA 1999; 282(5): 433-439.

[11] Bhui K, Craig T, Mohamud S, Warfa N, Stansfeld SA, Thornicroft $\mathrm{G}$, et al. Mental disorders among Somali refugees. Soc Psychiatry Psychiatr Epidemiol 2006; 41(5): 400-408.

[12] Mollica RF, Caspi-Yavin Y, Bollini P, Truong T, Tor S, Lavelle J. The Harvard Trauma Questionnaire: validating a cross-cultural instrument for measuring torture, trauma, and posttraumatic stress disorder in Indochinese refugees. J Nerv Ment Dis 1992; 180(2): 111-116.

[13] Momartin S, Silove D, Manicavasagar V, Steel Z. Dimensions of trauma associated with posttraumatic stress disorder (PTSD) caseness, severity and functional impairment: a study of Bosnian refugees resettled in Australia. Soc Sci Med 2003; 57(5): 775-781.

[14] Neuner F, Schauer M, Karunakara U, Klaschik C, Robert C, Elbert T. Psychological trauma and evidence for enhanced vulnerability for posttraumatic stress disorder through previous trauma among West Nile refugees. BMC Psychiatry 2004 Oct 25; 4: 34.

[15] Kessler RC, Sonnega A, Bromet E, Hughes M, Nelson CB. Posttraumatic stress disorder in the National Comorbidity Survey. Arch Gen Psychiatry 1995; 52(12): 1048-1060.

[16] De Jong JT, Komproe IH, Van Ommeren M, El Masri M, Araya M, Khaled N, et al. Lifetime events and posttraumatic stress disorder in 4 postconflict settings. JAMA 2001; 286(5): 555-562.

[17] Adams RE, Boscarino JA. Stress and well-being in the aftermath of the World Trade Center attack: The continuing effects of a communitywide disaster. J Commun Psychol 2005; 33(2): 175-190.

[18] Bracken PJ, Giller JE, Summerfield D. Psychological responses to war and atrocity: the limitations of current concepts. Soc Sci Med 1995; 40(8): 1073-1082.

[19] Kienzler H. Debating war-trauma and post-traumatic stress disorder (PTSD) in an interdisciplinary arena. Soc Sci Med 2008; 67(2): 218-227.

[20] McFarlane AC, Yehuda R. Clinical treatment of posttraumatic stress disorder: conceptual challenges raised by recent research. Aust N Z J Psychiatry 2000; 34(6): 940-953.

[21] Karam EG, Mneimneh ZN, Dimassi H, Fayyad JA, Karam AN, Nasser SC, et al. Lifetime prevalence of mental disorders in Lebanon: First onset, treatment, and exposure to war. PLoS Med 2008: 5(4): $579-586$

[22] United Nations Interim Force in Lebanon. United Nations Interim Force in Lebanon: Background. http://www.un.org/en/peace keeping/missions/unifil/background.shtml (accessed September 01 2009).

[23] Amnesty International. Israel/South Lebanon: Fear for safety Amnesty International. http://www.amnesty.org/en/library/info/ MDE15/078/1998/en (accessed Januarv 2010).

[24] United Nations Security Council. United Nations Security Council Renort: Rebort of the Secretarv-General on the United Nations Interim Force in Lebanon. United Nations. Report number: S/2005/36, January 202005.

[25] Farhood LF, Dimassi H. Prevalence and predictors for posttraumatic stress disorder, depression and general health in a population from six villages in South Lebanon. Soc Psychiatry Psychiatr Epidemiol 2012; 47(4): 639-649.

[26] Demyttenaere K, Bruffaerts R, Posada-Villa J, et al. WHO World Mental Health Survey Consortium: prevalence, severity, and unmet need for treatment of mental disorders in the World Health Organization World Mental Health Surveys. JAMA 2004; 291(21): 2581-2590.

[27] United Nations High Commissioner for Refugees (UNHCR). UNHCR: Internally Displaced People. http://www.unhcr.org/pa ges/49c3646c146.html (accessed August 25 2009).

[28] Cardozo BL, Kaiser R, Gotway CA, Agani F. Mental health, social functioning, and feelings of hatred and revenge of Kosovar Albanians one year after the war in Kosovo. J Trauma Stress 2003; 16(4): 351-360.
[29] Farhood LF. Testing a model of family stress and coping based on war and non-war stressors, family resources and coping among Lebanese families. Arch Psychiatr Nurs 1999; 13(4): 192-203.

[30] Michultka D, Blanchard EB, Kalous T. Responses to civilian war experiences: predictors of psychological functioning and coping. J Trauma Stress 1998; 11(3): 571-577.

[31] Abu-Saba MB. War-related trauma and stress characteristics of American University of Beirut students. J Trauma Stress 1999; 12(1): 201-207.

[32] Johnson H, Thompson A. The development and maintenance of post-traumatic stress disorder (PTSD) in civilian adult survivors of war trauma and torture: A review. Clin Psychol Rev 2008; 28(1): 36-47.

[33] Farhood L, Dimassi H, Strauss NL. Understanding Post-Conflict Mental Health: Assessment of PTSD, Depression, General Health and Life Events in Civilian Population One Year after the 2006 War in South Lebanon. 2013.

[34] Beck AT, Ward CH, Mendelson M, Mock J, Erbaugh J. An inventory for measuring depression. Arch Gen Psychiatry 1961; 4(6): 561-571.

[35] Goldberg DP, Hillier VF. A scaled version of the General Health Questionnaire. Psychol Med 1979; 9(01): 139-145.

[36] Beck AT, Steer RA, Carbin MG. Psychometric properties of the Beck Depression Inventory: Twenty-five years of evaluation. Clin Psychol Rev 1988; 8(1): 77-100.

[37] Farhood, LF, Noureddine, SN. PTSD, depression, and health status in Lebanese civilians exposed to a church explosion. The Int $\mathrm{J}$ Psychiatry Med 2003; 33(1): 39-53.

[38] Farhood, LF. Project report on: Mental health and psychosocial care - Postwar Lebanon, 2006 Phase I - Training of primary health care providers. World Health Organization 2006.

[39] Werneke U, Goldberg DP, Yalcin I, Üstün B. The stability of the factor structure of the General Health Questionnaire. Psychol Med 2000; 30(04): 823-829.

[40] Thabet A, Vostanis P. The Validity of the Arabic Version of the General Health Questionnaire in the Gaza Strip. Palestinian Med J 2005; 1: 33-36.

[41] Alqahtani MM, Salmon P. Prevalence of somatization and minor psychiatric morbidity in primary healthcare in Saudi Arabia: A preliminary study in Asir region. J Fam Commun Med 2008; 15(1): 27-33.

[42] Sadavoy J. Survivors: a review of the late-life effects of prior psychological trauma. Am J Geriatr Psychiatry 1997; 5(4): 287 301 .

[43] Amir M, Sol O. Psychological impact and prevalence of traumatic events in a student sample in Israel: The effect of multiple traumatic events and physical injury. J Trauma Stress 1999; 12(1): 139-154.

[44] Nuwayhid I, Zurayk H, Yamout R, Cortas CS. Summer 2006 war on Lebanon: A lesson in community resilience. Global Public Health 2011; 6(5): 505-519.

[45] McFarlane AC, Yehuda R. Resilience, vulnerability, and the course of posttraumatic reactions. In: Van der Kolk, BA, McFarlane, AC, Weisaeth, L, Eds. Traumatic stress: the effects of overwhelming experience on mind, body, and society. New York: Guilford Press; 1996. pp. $155-158$.

[46] Norris FH, Tracy M, Galea S. Looking for resilience: Understanding the longitudinal trajectories of responses to stress. Soc Sci Med 2009; 68(12): 2190-2198.

[47] Freedy JR, Hobfoll SE, Ribbe DP. Life events, war and adjustment: Lessons for the Middle East. Anxiety, Stress, Coping 1994; 7(3): 191-203.

[48] Somasundaram DJ, Sivayokan S. War trauma in a civilian population. Br J Psychiatry 1994; 165(4): 524-527.

[49] Summerfield D. War and mental health: a brief overview. BMJ 2000; 321(7255): 232-235. 